\section{Item Difficulty}

Michael Franzen

Allegheny General Hospital, Pittsburgh, PA, USA

\section{Definition}

Item difficulty is an estimate of the skill level needed to pass an item. It is frequently measured by calculating the proportion of individuals passing an item. In order to increase efficient use of both the examiner's and the examinee's time, the item difficulty index values can be used to order the administration items so that a discontinue rule can be invoked to reduce the administration of more difficult items to individuals who would be unlikely to pass them.

\section{Current Knowledge}

Another method of measuring item difficulty for developmental tests is to calculate the age at which some proportion of individuals would pass the item. If $50 \%$ of individuals aged 3 years pass an item, that item might be said to have an age equivalency of 3 years. The items can then be arranged in increasing order of age equivalency so that the difficulty level increases throughout the test.

\section{Cross-References}

Item Analysis

\section{References and Readings}

de la Plata, C. M., Arango-Lasprilla, J. C., Alegret, M., Moreno, A., Tárraga, L., Lara, M., Hewlitt, M., Hynan, L., \& Cullum, C. M. (2009). Item analysis of three Spanish naming tests: A cross-cultural investigation. NeuroRehabilitation, 24, 75-85.

Lord, F. M., \& Novick, M. R. (1968). Statistical theories of mental test scores. Reading: Addison-Wesley. 